OPEN ACCESS

Edited by:

Rob Harcourt,

Macquarie University, Australia

Reviewed by:

Richard Reina,

Monash University, Australia

*Correspondence:

Travis Longcore

longcore@ucla.edu

Specialty section:

This article was submitted to

Marine Megafauna

a section of the journal

Frontiers in Marine Science

Received: 10 June 2020

Accepted: 03 August 2020

Published: 17 September 2020

Citation:

Longcore T, Duriscoe D, Aubé M,

Jechow A, Kyba CCM and

Pendoley KL (2020) Commentary:

Brightness of the Night Sky Affects

Loggerhead (Caretta caretta) Sea

Turtle Hatchling Misorientation but Not

Nest Site Selection.

Front. Mar. Sci. 7:706.

doi: 10.3389/fmars.2020.00706

\section{Commentary: Brightness of the Night Sky Affects Loggerhead (Caretta caretta) Sea Turtle Hatchling Misorientation but Not Nest Site Selection}

\author{
Travis Longcore ${ }^{1 *}$, Dan Duriscoe ${ }^{2}$, Martin Aubé $^{3}$, Andreas Jechow ${ }^{4,5}$, \\ Christopher C. M. Kyba ${ }^{4,5}$ and Kellie L. Pendoley ${ }^{6}$ \\ ${ }^{1}$ UCLA Institute of the Environment and Sustainability, Los Angeles, CA, United States, ${ }^{2}$ Night Sky Metrics LLC, Woodland \\ Hills, CA, United States, ${ }^{3}$ Cégep de Sherbrooke, Sherbrooke, QC, Canada, ${ }^{4}$ Leibniz-Institute of Freshwater Ecology and \\ Inland Fisheries, Berlin, Germany, ${ }^{5}$ GFZ German Research Centre for Geosciences, Potsdam, Germany, ${ }^{6}$ Pendoley \\ Environmental Pty Ltd, Perth, WA, Australia
}

Keywords: light pollution, sea turtles, light measurement, photometry, glare, sky quality meter

\section{A Commentary on}

Brightness of the Night Sky Affects Loggerhead (Caretta caretta) Sea Turtle Hatchling Misorientation but Not Nest Site Selection

by Stanley, T. R., White, J. M., Teel, S., and Nicholas, M. (2020). Front. Mar. Sci. 7:221. doi: $10.3389 /$ fmars.2020.00221

\section{INTRODUCTION}

As research in the field of artificial light at night has increased and more sophisticated quantification of the influence of light is required, ecologists have been seeking a method to quickly and costeffectively measure artificial light at night. Measuring light at night in a biologically meaningful way is complicated, and requires specialist knowledge (Swaddle et al., 2015; Hänel et al., 2018). It is therefore potentially tempting to adopt tools developed for other disciplines, such as the low-cost and easy-to-use radiance meter "Sky Quality Meter" (SQM), and the SQM-L model, which have both been widely used in night sky brightness studies. Unfortunately, in some cases these instruments are being used for purposes beyond which they were intended. Stanley et al. (2020) used SQMs to make observations of radiance from a series of points on the sky dome, with the intention of thereby measuring hemispherical light levels, to investigate their influence on sea turtle nesting location and hatchling behavior. We appreciate their intention to measure angularly resolved radiance, their analysis and conclusions, and do not disagree with their ultimate recommendations. However, we are concerned that the radiance data are unreliable because of an inadvisable use of an SQM. For this reason, we recommend that researchers do not use SQMs to measure light from very heterogeneous scenes (including the horizon) for biological and ecological studies, because those data could be difficult to reproduce and interpret, and therefore open to challenge. 


\section{SKY QUALITY METERS SHOULD NOT BE USED TO MEASURE HORIZON BRIGHTNESS}

The problem with using SQMs to measure horizon and near horizon brightness arises because the SQM is designed to make observations of a roughly homogeneous field of light without bright glare sources. First, the horizon does not match this description, as it demarcates a dramatic transition in brightness between the land or sea and the sky. In artificially lit locations it can also include illuminated objects or bright point sources of light. Unless extraordinary care is taken to position and direct the SQM identically from one observation to the next, an observation from an SQM aimed toward the horizon will not be replicable, leading to a measurement error. Second, when aimed at the horizon, the field of view includes the area below the horizon, resulting in average radiance much less than the brightness of the sky in the region (Duriscoe et al., 2015). Third, manufacturer instructions for use of the SQM warn that direct glare on the faceplate sensor should be avoided to prevent light being reflected internally. Fourth, in the presence of bright sources near horizon the SQM will overestimate radiance of the sky even if the SQM does not point close to horizon (Duriscoe et al., 2015). This is because the sensitivity of the SQM at high angles is still not zero and can reach about $2 \%$ of its maximal sensitivity up to $70^{\circ}$ from the pointing direction (Sánchez de Miguel et al., 2017).

Recommendations for using an SQM were provided by Hänel et al. (2018). They described the measurement error in the instrument, and recommended intercalibration and methods for data collection to reduce error (i.e., reject first few readings, allow the SQM to warm up, rotate the SQM around all 4 cardinal directions while aiming at the zenith etc.). Cinzano $(2005,2007)$ provided an early review on the use, precision and accuracy of SQM, and a growing body of literature has built on this work (for example see den Outer et al., 2011, 2015; Duriscoe et al., 2015; Sanchez et al., 2017). Stanley et al. (2020) used a tripod for pointing, but otherwise did not report following these recommended methods.

\section{DISCUSSION}

Stanley et al. (2020) are not alone in the inappropriate use of SQMs to measure light at the horizon. Other papers and

\section{REFERENCES}

Barentine, J. C. (2019). Methods for assessment and monitoring of light pollution around ecologically sensitive sites. J. Imaging 5:54. doi: 10.3390/jimaging5050054

Bonner, R. (2015). The Impact of Photopollution on Nesting Loggerhead Sea Turtles (Caretta caretta) Along the Grand Strand (M. S. Thesis). Coastal Carolina University. Available online at: https://digitalcommons.coastal.edu/etd/3

Cinzano, P. (2005). Night Sky photometry With Sky Quality Meter. ISTIL Int. Rep, 9.

Cinzano, P. (2007). Report on Sky Quality Meter, Version L. ISTIL Int. Report.

den Outer, P., Lolkema, D., Haaima, M., van der Hoff, R., Spoelstra, H., and Schmidt, W. (2011). Intercomparisons of nine sky theses have been published with this approach (e.g., Bonner, 2015; Kelly et al., 2017; Price et al., 2018; Windle et al., 2018). We hope that future research on light pollution in coastal environments, and in ecology more broadly, avoids this misuse of the SQM for horizon measurements. Studies that use an SQM for skyglow monitoring should, as a minimum, avoid the region up to 30 degrees above the horizon, and report all details of the SQM configuration, specifications, and data collection methods used, including viewing angles and directions, presence of point sources toward the horizon, and values and variance of replicate measurements, to provide confidence in the precision and accuracy of the results (Zamorano et al., 2014). Biologists should familiarize themselves with the operation and limitations of the SQM, and the potential complicating factors influencing measurement, such as the airglow band between the horizon and 20 degrees above it, clouds, and atmospheric aerosols. We encourage biologists to explore other options that are now becoming more readily available to measure both point source lights and sky glow, at or near the horizon. The most widely recommended method is digital camerabased photography (using a fisheye lens to capture the whole sky). When correctly calibrated, this method provides both qualitative (imagery) and quantitative (skyglow radiance) data (Hänel et al., 2018; Barentine, 2019; Jechow et al., 2019). While slightly more expensive, this technique can be used to examine different sectors of the sky accurately, allowing better quantification of local conditions that may be important to species responses.

\section{AUTHOR CONTRIBUTIONS}

TL and KP wrote the first draft. All authors contributed to, reviewed, and edited the final text.

\section{FUNDING}

CK acknowledged funding from the the European Union's Horizon 2020 research and innovation programme ERAPLANET, grant agreement no. 689443, via the GEOEssential project, and from the Helmholtz Association Initiative and Networking Fund under grant ERC-RA-0031. AJ acknowledged support from the Leibniz Association via CONNECT (SAWK45/2017) and ILES (SAW- 2015-IGB-1) projects.

brightness detectors. Sensors 11, 9603-9612. doi: 10.3390/s1110 09603

den Outer, P., Lolkema, D., Haaima, M., van der Hoff, R., Spoelstra, H., and Schmidt, W. (2015). Stability of the nine sky quality meters in the Dutch night sky brightness monitoring network. Sensors 15, 9466-9480. doi: 10.3390/s150409466

Duriscoe, D., White, J., Moore, C., Tekatch, A., and Welch, D. (2015). "Use of the SQM-L for all-sky light pollution measurement," in Conference: Light Pollution, Theory Modeling and Measurements 2015 (Jouvence, QC).

Hänel, A., Posch, T., Ribas, S. J., Aubé, M., Duriscoe, D., Jechow, A., et al. (2018). Measuring night sky brightness: methods and challenges. J. Quant. Spectrosc. Radiat. Transf. 205, 278-290. doi: 10.1016/j.jqsrt.2017. 09.008 
Jechow, A., Kyba, C. C. M., and Hölker, F. (2019). Beyond all-sky: assessing ecological light pollution using multi-spectral full-sphere fisheye lens imaging. J. Imaging 5:46. doi: 10.3390/jimaging5040046

Kelly, I., Leon, J. X., Gilby, B. L., Olds, A. D., and Schlacher, T. A. (2017). Marine turtles are not fussy nesters: a novel test of small-scale nest site selection using structure from motion beach terrain information. PeerJ 5:e2770. doi: $10.7717 /$ peerj.2770

Price, J. T., Drye, B., Domangue, R. J., and Paladino, F. V. (2018). Exploring the role of artificial lighting in loggerhead turtle (Caretta caretta) nestsite selection and hatchling disorientation. Herpetol. Conserv. Biol. 13, $415-422$.

Sánchez de Miguel, A., Aubé, M., Zamorano, J., Kocifaj, M., Roby, J., and Tapia, C. (2017). Sky Quality Meter measurements in a colour-changing world. Mon. Not. R. Astron. Soc. 467, 2966-2979. doi: 10.1093/mnras/ stx145

Stanley, T. R., White, J. M., Teel, S., and Nicholas, M. (2020). Brightness of the night sky affects Loggerhead (Caretta caretta) sea turtle misorientation but not nest site selection. Front. Mar. Sci. 7:221. doi: 10.3389/fmars.2020. 00221

Swaddle, J. P., Francis, C. D., Barber, J. R., Cooper, C. B., Kyba, C. C., Dominoni, D. M., et al. (2015). A framework to assess evolutionary responses to anthropogenic light and sound. Trends Ecol. Evol. 30, 550-560. doi: $10.1016 /$ j.tree.2015.06.009
Windle, A. E., Hooley, D. S., and Johnston, D. W. (2018). Robotic vehicles enable high-resolution light pollution sampling of sea turtle nesting beaches. Front. Mar. Sci. 5:493. doi: 10.3389/fmars.2018.00493

Zamorano, J., Sánchez de Miguel, A., Nievas, M., and Tapia, C. (2014). NixNox Procedure to Build Night Sky Brightness Maps From SQM Photometers Observations. LICA report, v. 1.1.

Conflict of Interest: TL was employed by the University of California, Los Angeles and by the company Land IQ. DD was employed by the company Night Sky Metrics LLC. KP was employed by the company Pendoley Environmental Pty Ltd.

The remaining authors declare that the research was conducted in the absence of any commercial or financial relationships that could be construed as a potential conflict of interest.

Copyright $\odot 2020$ Longcore, Duriscoe, Aubé, Jechow, Kyba and Pendoley. This is an open-access article distributed under the terms of the Creative Commons Attribution License (CC BY). The use, distribution or reproduction in other forums is permitted, provided the original author(s) and the copyright owner(s) are credited and that the original publication in this journal is cited, in accordance with accepted academic practice. No use, distribution or reproduction is permitted which does not comply with these terms. 